\title{
A Case of Shingles Following Auricular Acupuncture
}

\author{
Steven A. Kewish, MD
}

This is a case report of an occurrence of shingles (herpes zoster [HZ]) following auricular acupuncture. The patient developed acute reactivation $\mathrm{HZ}$ in the $\mathrm{V} 1$ distribution of the right trigeminal nerve involving the forehead, scalp, and medial upper eyelid 13 days after being treated with auricular acupuncture for chronic low-back pain. The lesions were initially painless, but they clustered and became painful within 2 days. The patient was treated with oral valacyclovir $1000 \mathrm{mg}, 3$ times daily for 7 days, and ibuprofen as needed. The lesions resolved without sequelae.( $\mathrm{J}$ Am Board Fam Med 2017;30:552-555.)

Keywords: Acupuncture Therapy, Herpes Zoster, Low Back Pain, Trigeminal Nerve, Valacyclovir

A 53-year-old male patient sought treatment for chronic low-back pain through auricular acupuncture. A standard "battlefield acupuncture" technique was applied to reduce pain (Figure 1). This technique calls for the use of 5 semipermanent needles applied to specific points on 1 or both ears. The patient recalls the initial Aiguille Semi-Permanente (ASP) needle, placed at the base of the right intertragic notch (labeled "cingulate gyrus" in Figure 1), causing a shocklike sensation. Additional ASP needles were placed bilaterally at the left cingulate gyrus and at the midantitragus (labeled "thalamus" in Figure 1). None of the subsequent needles caused the same shocklike sensation. These were the only ASP needles used, and they remained in place for 48 hours, after which they became loose and fell out. The treatment succeeded in relieving the patient's low-back pain for about 10 days. Approximately 12 days after the acupuncture session, the patient reported that he began feeling mild malaise, which he treated with rest. The following

This article was externally peer reviewed.

Submitted 15 February 2017; revised 18 February 2017; accepted 21 February 2017.

From the Naval Hospital Bremerton, Bremerton, WA.

Current affiliation: NATO Role 3 Multinational Medical

Unit, Kandahar, Afghanistan.

Funding: none.

Conflict of interest: none declared.

Corresponding author: Steven A. Kewish, MD, Family Medicine, 1 Boone Road, Bremerton, WA 98312 (E-mail: steven.kewish@yahoo.com). morning he awoke and noticed an area of redness just below the hairline on the right forehead. As the day progressed the area became larger, and by the end of the day, a small cluster of vesicles had appeared. The next morning a second cluster developed, beginning above the hairline on the right and extending down in a narrow broken line toward the medial right eyebrow and terminating near the medial canthus (Figure 2). Neither of these were initially painful but "tingling" was noted. The patient visited his family physician, who diagnosed him with shingles in the V1 distribution of the trigeminal nerve. The patient was subsequently evaluated by an ophthalmologist, who found no ocular involvement.

This patient had a history of chicken pox at age 10 , no history of herpes zoster (HZ), and had never received Zostavax or a varicella titer. A detailed history and physical examination of this patient revealed no significant acute or chronic medical conditions, and no other issues predisposing to the development of shingles.

Standard treatment for $\mathrm{HZ}$ was initiated with valacyclovir, and symptoms were managed with oral ibuprofen. The patient's symptoms resolved without complication and, at the time of this writing, had not returned.

\section{Case Review}

Acupuncture is frequently used for the treatment of pain associated with shingles, but auricular acu- 
Figure 1. Approximate needle insertion sites for Battlefield Acupuncture.

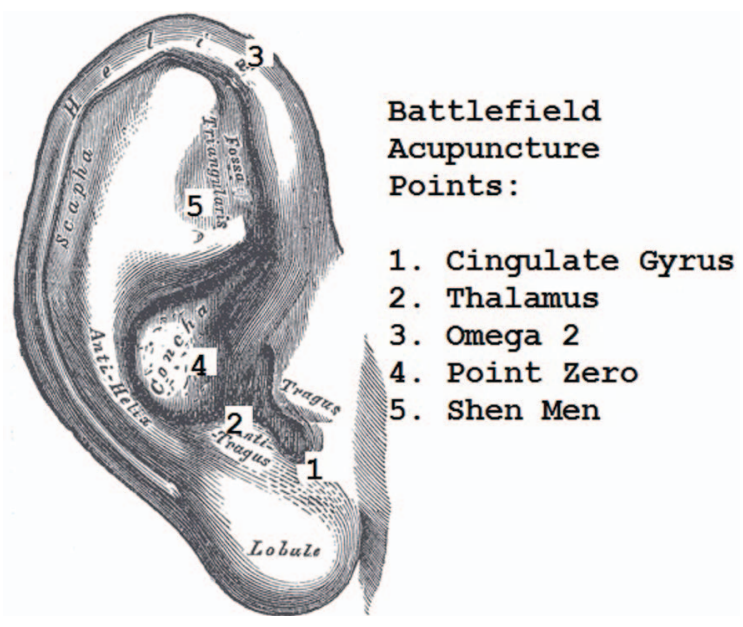

puncture has not, to my knowledge, previously been described as being associated with $\mathrm{HZ}$ reactivation. Numerous other potential side effects are known; however, only 1 primary source document was located showing an association between acupuncture and herpes. ${ }^{1-3}$ A literature review noted several cases of trauma-induced trigeminal nerve zoster, but none were specifically associated with auricular acupuncture (Figures 1-3).

\section{Discussion}

After acute varicella zoster infection, the virus migrates up sensory axons and becomes latent in regional ganglia or nuclei, where it remains dormant, often for years. Trigeminal nerve nuclei and thoracic spinal ganglia are the most commonly affected. Under certain conditions, the virus reactivates and travels to the dermatome corresponding to its nucleus or ganglion, producing the typical painful, vesicular rash of shingles. Recurrence can happen at different ages and in different locations in the same person. Typically, however, subsequent cases are progressively less common. Precipitating factors for shingles include stress, trauma, chronic disease, systemic illness, and immune disorders, among others. ${ }^{2,3}$ Reactivation is also influenced by the age-related waning of immunologic response by the host to the virus, prompting the recommendation for shingles vaccination. While Zostavax is approved by the FDA for use in patients aged 50 years and older, the Centers for Disease Control and Prevention recommend routine vaccina- tion starting at age 60, largely because of the limited vaccine supply and a lower incidence of postherpetic neuralgia among people in their $50 \mathrm{~s}$ (based on the Centers for Disease Control and Prevention and Advisory Committee of Immunization Practices 2014 guidelines).

Acupuncture is a procedure that represents a minor trauma. Physical trauma and surgical procedures are known to precipitate $\mathrm{HZ}$ eruptions, including in cranial nerve distributions. ${ }^{4-7}$ A case-control study in 2012 noted an increased proportion of trauma in $\mathrm{HZ}$ cases compared with controls in any of the 52 weeks before the onset of symptoms; the greatest proportion occurred in the first week. In addition, patients diagnosed with cranial $\mathrm{HZ}$ were $>25$ times as likely as controls to have had cranial trauma during the week before $\mathrm{HZ}$ onset. ${ }^{8}$ A casecontrol study by Thomas et $\mathrm{al}^{4}$ in 2004 concluded that recent trauma was associated with an adjusted 12 -fold increase in the risk of developing $\mathrm{HZ}$ at the site of the trauma within 1 month. Mechanisms by which trauma might reactivate the zoster virus are not specifically known, but stimula-

\section{Figure 2. Shingles in the V1 distribution of the Trigeminal Nerve.}

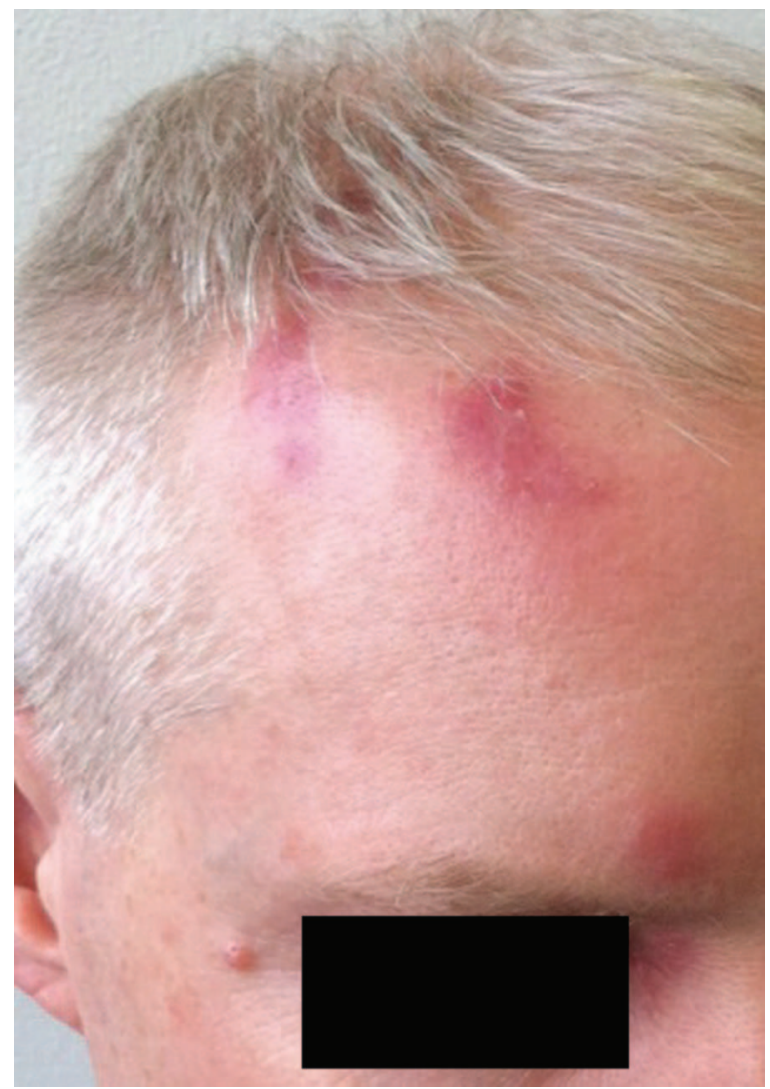


Figure 3. Anatomy of the Trigeminal Nerve.

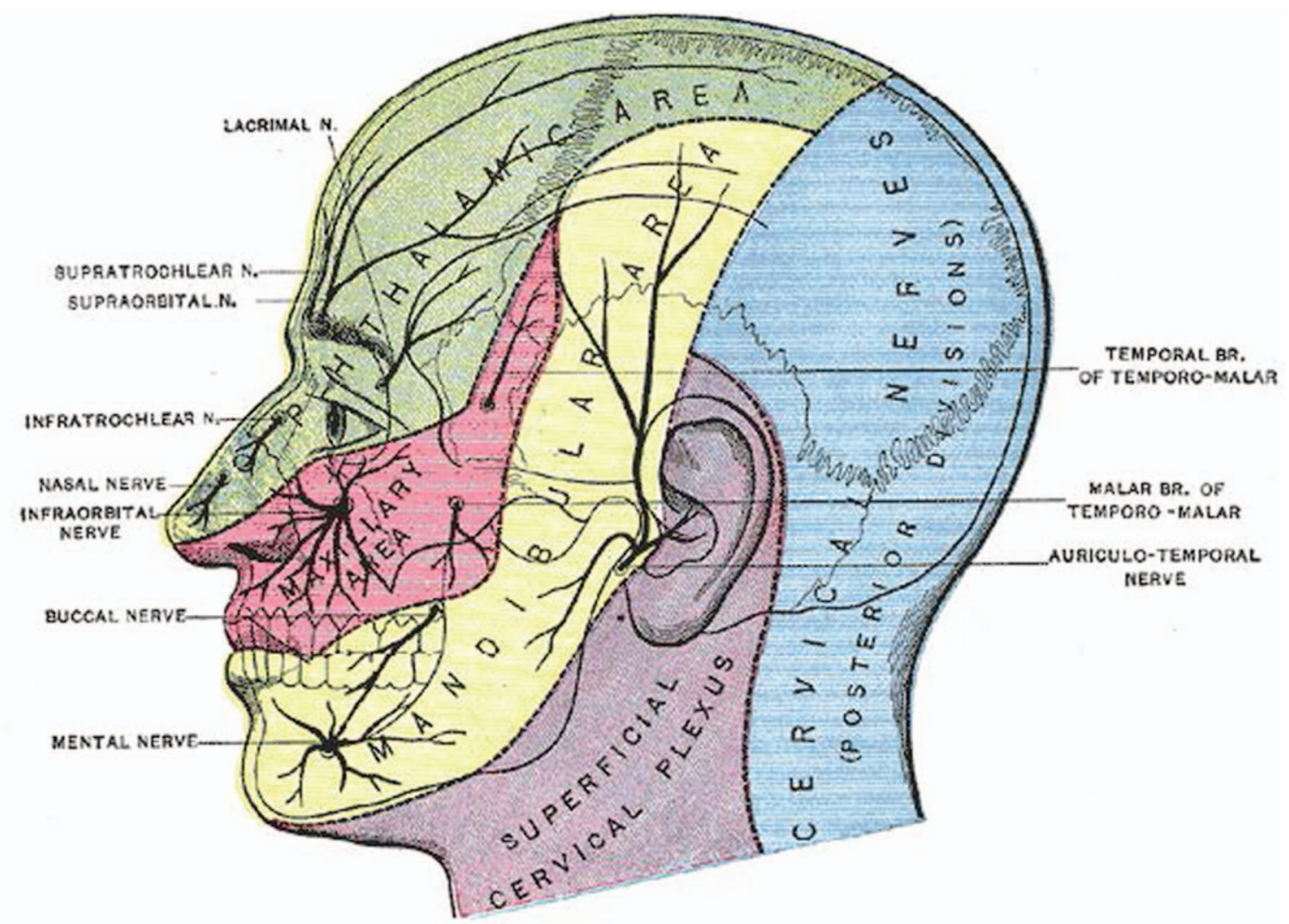

tion of nerve nuclei or ganglia is proposed. The literature suggests that outbreaks are most likely to occur within the first month after the insult. Although cause and effect cannot be proven in this case, the timing, mechanism, and proximity to the acupuncture "trauma" are compelling. The proposed explanation for triggering the onset of reactivation $\mathrm{HZ}$ in this patient is stimulation of the trigeminal nuclei, perhaps via a branch of the auriculotemporal nerve, secondary to the acupuncture (Figure 3).

\section{Recommendations}

$\mathrm{HZ}$ is a painful disease process with potential for significant morbidity. Auricular acupuncture is becoming more widely used in outpatient settings because of its quick and easy application, effectiveness, and presumed safety. In the military, battlefield acupuncture describes a limited auricular acupuncture technique used to treat pain, and this technique is common ${ }^{9}$ (Figure 1). The 2 most common complications of acupuncture are pneumothorax and hepatitis. When counseling susceptible individuals, shin- gles should be considered as an additional, yet less common, risk of this procedure. Verbal screening for a history of varicella or shingles, monitoring after treatment, and perhaps applying prophylaxis for atrisk populations should considered.

To see this article online, please go to: http://jabfm.org/content/ 30/4/552.full.

\section{References}

1. Chang TW. Letter: activation of cutaneous herpes by acupuncture. N Engl J Med 1974;290:1310.

2. Rampes H, James R. Complications of acupuncture. Acupunct Med 1995;13:26-33.

3. White AA. Cumulative review of the range and incidence of significant adverse events associated with acupuncture. Acupunct Med 2004;22:122-33.

4. Thomas SL, Wheeler JG, Hall AJ. Case-control study of the effect of mechanical trauma on the risk of herpes zoster. BMJ 2004;328:439-40.

5. Mansour N, Kaliaperumal C, Choudhari KA. Facial herpes zoster infection by surgical manipulation of the trigeminal nerve during exploration of the posterior fossa: a case report. J Med Case Rep 2009;3: 7813. 
6. Lin KC, Wang CC, Wang KY, Liao YC, Kuo JR. Reactivation of herpes zoster along the trigeminal nerve with intractable pain after facial trauma: a case report and literature review. BMJ Case Rep 2009;2009:pii. DOI: 10.1136/bcr.07.2008.0525.

7. Foye PM, Stitik TP, Nadler SF, Chen BA. Study of posttraumatic shingles as a work related injury. Am J Ind Med 2000;38:108-11.
8. Zhang JX, Joesoef RM, Bialek S, Wang C, Harpaz R. Association of physical trauma with risk of herpes zoster among Medicare beneficiaries in the United States. J Infect Dis 2013;207:1007-11.

9. Jonas WB, Welton RC, Delgado RE, Gordon S, Zhang W. CAM in the United States military: too little of a good thing? Med Care 2014;52(12 Suppl 5):S9-12. 